\title{
FTA ANALYSIS OF THE FAULT IN THE HORIZONTAL FLUIDITY TEST
}

\author{
Peter Blaško, Jozef Petrík ${ }^{*}$ \\ Technical University of Košice, Faculty of Metallurgy, Košice, Slovakia
}

Received 04.06.2015

Accepted 22.09.2015

\begin{abstract}
The purpose of the paper was to evaluate the probability of the top event in the fluidity test by Fault Tree Analysis (FTA). One of the important tests used in the foundry practice is the test of the fluidity. Fluidity is the ability of the molten metal to fill the cavity of the molds and create a cast. The AlSi10MgMn (EN 1706) alloy with 5 or $10.54 \%$ of silica was the experimental material. The melted alloy was cast into "horizontal" three-channel mold to test its fluidity. The pouring temperatures were between 605 and $830{ }^{\circ} \mathrm{C}$. In some cases, the experiment was not successful, for a some reasons. This fact led to a waste of time, energy, potential risk of accident, confusion among participants, especially "beginners" founders and became an impulse for the analysis of creation and possible events of fault for the fluidity test using the FTA. It has been found that for the probability of the top event in examined process was disproportionately high (0.29824). The Monte Carlo method was used for the simulation of the effect of decreasing the probability of basic events on the probability of the top event - the fault of the fluidity test.

Keywords: Fluidity test, Fault Tree Analysis (FTA), Monte Carlo Method
\end{abstract}

\section{Introduction}

The measurement is a process of experimentally obtaining one or more quantity values that can reasonably be attributed to a quantity [1]. We treat measurement process as any process that needs to be managed. It begins with traceability of the measuring device values of standards. It continues through metrological confirmation to the measurement of specific staff of appraisers under the action of influence quantities. The measuring process is carried out in a system, including, in particular, a measurement device, used method, appraiser (founder), measured samples and environmental conditions that affect the elements of the process. Methods for managing the measurement system are based on regular monitoring and analysis of measured data [2].

"Corresponding author: Jozef Petrík, jozef.petrik@tuke.sk 
Metal casting has its history, and one of the oldest types of metalworking is foundry production. People found that metal, which is melted and then poured into the cavity, obtains the shape of the cavity (the product) [3].The production of casting with a particular quality highly depends on values of casting properties of the alloys and casting metals. Casting properties are those properties that ensure the possibility to create the mold with required mechanical and other operating properties by the simplest and the cheapest technological steps [4].

\section{Experimental materials and procedure}

One of the important tests used in foundry practice is the test of the fluidity. Fluidity is the ability of a molten metal to fill the cavity of the molds and create a cast. It is measured by pouring molten metal into a standard mold that provides a good indication of metal flow. Usually, a thin, long casting is poured in the form of a spiral or a rod, the length of the spiral serving as a measure of fluidity. Both metal and mold characteristics are involved in determining the fluidity. As far as metal characteristics are concerned, the following metallurgical factors can be listed as those, which have greater or lesser effect on fluidity [3], [5].

There are not standards for fluidity, and, therefore, it is difficult to determine the capability of the measurement system of this parameter by the analysis of uncertainty.

Unlike the surface tension or liquidity, which are the physical properties of the liquid metal, the fluidity is the technological property that is the result of many factors affecting the filling the mold with a metal. The factors are mainly:

- Alloy properties (viscosity, surface tension, density, thermal conductivity...)

- The metal temperature during casting

- Inlet system

- Mold properties (thermal conductivity, density, coefficient of friction of melted metal or the walls of the mold)

- The shape of solidified casting

- The environment (temperature, pressure, geo-climatic conditions) [3], [6].

To determine the fluidity different technological tests are used, which besides the fluidity test of casting steel are not standardized [7].

It should be mentioned that the measurement results are comparable only to fluidity test under the same conditions of the molds and casting techniques. It is necessary to follow the selected test conditions strictly. The casting temperature fluctuation even by a few degrees causes far greater uncertainty than any other condition in fluidity test. To have the fluidity test useful is necessary to make this test sufficiently sensitive and well reproducible. The capability analysis gives the information about the fluidity test suitability [8].

The alternative is tests called tests with a variable cross-section (V-belts, ballpoints test of Spassky), which give an indication of the ability of the melted metal to fill very thin sections. It is useful for the alloys on the surface, which produce the oxidize coating [3], [7], [9]. 


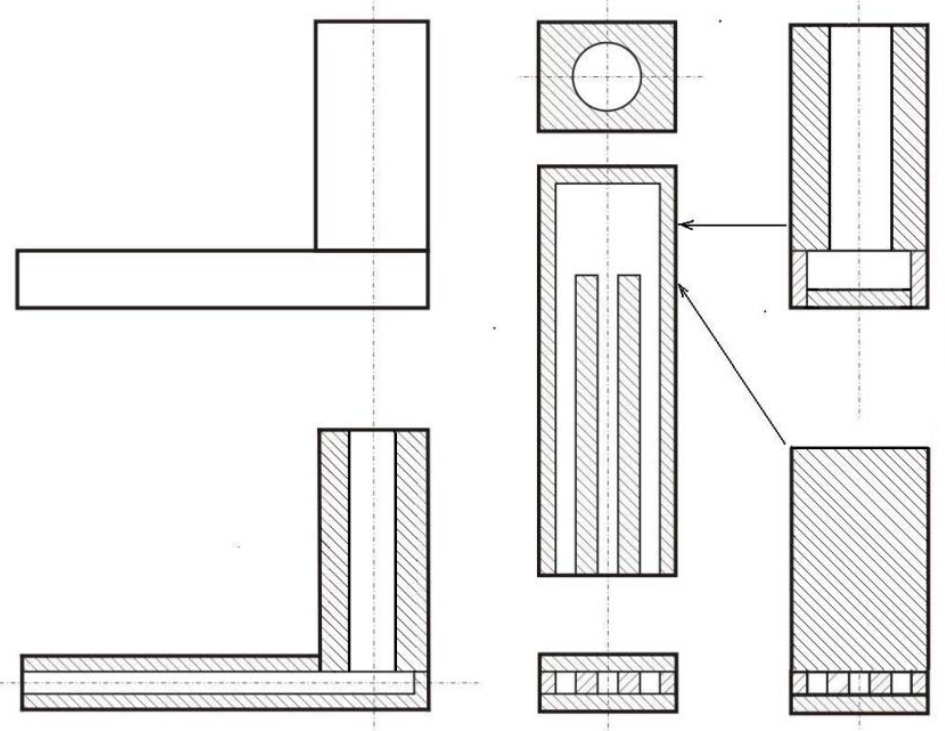

Fig. 1. The sketch of the mold.

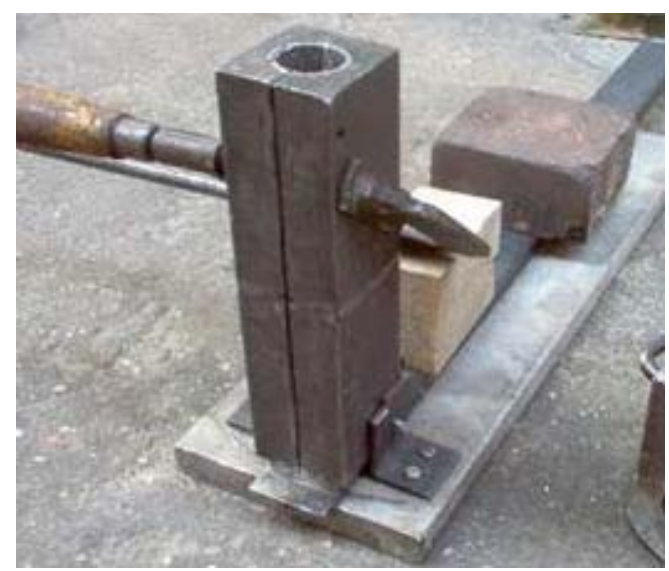

Fig. 2. Horizontal mold.

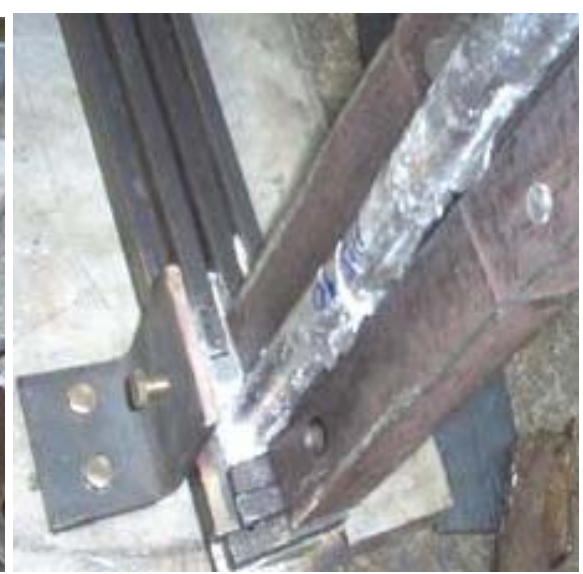

Fig. 3. The channels in the core.

The primary purpose of the experiment was to determine the influence of various factors (chemical composition, founder, the temperature of the melted alloy) on the fluidity of selected alloy using a horizontal mold. The AlSil0MgMn (EN 1706) alloy with 5 or $10.54 \%$ of silica was the experimental material. The iron (up to $0.15 \%$ ) is the polluting element.

The charge was melted in the chamotte - graphite crucible in electric resistance furnace, heated with six silit heating elements. The temperature in the furnace can be controlled automatically with a possible manual adjustment (fine tuning of the value of 
the electric current independently in each phase). The casting temperatures were 605 , $650,670,680,700,720,750,760,780$ and $830^{\circ} \mathrm{C}$; the pouring velocity was about 200 g.s $^{-1}$. The melt temperature was measured by the chrome-alumni submersible thermocouple in a protective ceramic case by calibrated analog temperature gauge.

When the required temperature of the melted alloy was reached, the crucible was removed from the furnace and the surface of the melted alloy was cleaned from the dross (oxide film). This operation has no practical effect of reducing the temperature of the melted alloy. The modifiers of the eutectic silica, grain refiners, and the degassing salts were not applied. The treated melted alloy was then poured into the "horizontal" bar-type three-channel mold to test its fluidity. The tree-channel system, described below allows creating conditions of the repeatability for the Measurement Systems Analysis (MSA) [10]. This arrangement is possible to reduce the number of experiments. The results amended by a computer simulation (software Novaflow\&Solid) have been published in [11 - 13].

The mold used for the test (Figs. 1,2) is designed as a demountable the parts are screwed together. The core (channels and bottom) is constructed of the steel STN 41 1375 (is comparable with EN S235 JRG 2). The core is connected to a massive base plate of aluminum alloy to eliminate a possible distortion and to ensure its horizontal position. The solid steel mold with the height $280 \mathrm{~mm}$ and with the diameter of the channel $20 \mathrm{~mm}$ was the sprue (Fig. 3).The pouring basin has a shape of the funnel. The height of all three horizontal channels is $10 \mathrm{~mm}$ and width $5 \mathrm{~mm}$ (the cross-section 50 $\mathrm{mm}^{2}$ ). Wall thickness between channels is $10 \mathrm{~mm}$ (Fig. 2) and a channel length of 700 $\mathrm{mm}$. The core is overlaid with steel plate and the refractory blocks. Baffles of the melt inserted into the square area - the gate below the sprue eliminate the negative impact of sharp angles. The mold was pre-heated at $120^{\circ} \mathrm{C} \pm 10^{\circ} \mathrm{C}$ prior the casting.

After solidification of the casting and after releasing the screws the cast was released without any problems. The temperature of the mold was measured by thermocouples in four points. The problem was to achieve the interplay between required temperature of the melt and the mold. The temperature of the mold decreased rapidly.

The number of experiments shall remain high despite the simplification achieved by using of the three-channel system. In some cases, the experiment was not successful, for some reasons. This fact led to a waste of time, energy, a potential risk of accident, and confusion among participants, especially "beginners" founders. This fact became an impulse for the analysis of the creation and possible events of fault for the fluidity test using the Fault Tree Analysis (FTA).

The Cause and Effect Diagram (Ishikawa) facilitates the construction of the fault tree. Based on the "diagram" and the "tree", the basic events were identified. Statistical data (probability of occurrence) of basic events were covered with 251 measurements in the experiment. Possibly (if available) were also used data for a longer period, particularly for rarely occurring basic events. Basic events give rise to the top event. Knowledge of the probability of occurrence of basic events allows estimating the probability of the top event. The type of individual gates and calculation of the probability of the top event, namely the fault of the test was carried out after constructing the tree. In the present case, top event is defined as the fault of the measurement process. It is not possible to create a casting, applicable to establish the value of the fluidity if there is a top event (or the casting so obtained is unusable for the 
measurement of the fluidity). The probability of the top event was calculated using the quantitative analysis of the fault tree followed by Monte Carlo simulation.

\section{Ishikawa diagram}

To prepare a fault tree analysis an Ishikawa or fishbone diagram was used, also called cause and effect diagram. It is a visualization tool for categorizing the potential causes of the problem - the top event to identify its root causes. The design of the diagram looks much like a skeleton of a fish. Fishbone diagrams are typically worked right to left, with each large "bone" - "ribs" of the fish branching out to include smaller bones containing more detail. The head and backbone of the fish list the top event - the problem or issue to be studied. Four "causes" that contribute to the problem (environment, source of electrical power, a construction element of the tester and quality of the test item) create the first bones (ribs) of the fish. Other, more specific levels of bones (horizontal, vertical, horizontal...) can be added to the "ribs" until the cause of the problem can be divided into subcategories. The practical number of levels is usually 4 to 5 . The lowest level is a basic event. When the diagram is complete, we provide an overview of the possible causes (not symptoms) of the solved problem. It is important to explore more times repeating subcategories to find a link between them, or eliminate unnecessary duplication (in triplicate). Correctly designed diagram significantly facilitates the design of fault tree analysis. The diagram of the analyzed process is in Fig. 4 [14].

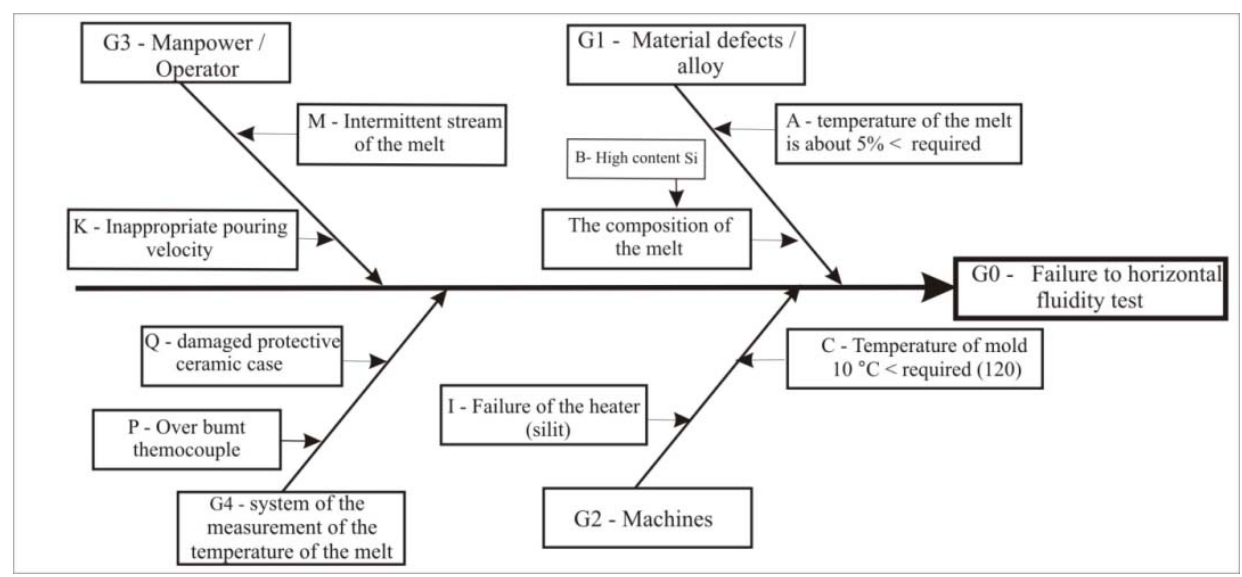

Fig. 4. Ishikawa diagram.

\section{The Fault Tree Analysis}

The method of Fault Tree Analysis (FTA) is a qualitative - quantitative analysis of the fault of the system in the form of the fault tree to determine as defined top event causing. However, it may potentially cause or contribute to the occurrence of elementary faults of lower-lying elements or external influences [15].

FTA method was first used in 1962 by Bell Telephone Laboratories in the development of intercontinental ballistic missiles (Minuteman Intercontinental Ballistic Missile Launch Control System) and was improved by Boeing in 1966. It started to be used in the nuclear power industry since 1975. Its use in this industry experienced a 
significant increase after an accident in Tree Mile Island in 1979. It is an important part of the liability engineering.

When Fault Tree Analysis proceeds step by step, the specific sequence of steps is not unified for all systems. The below sequence of steps is the minimum that must be included in each analysis:

1. Defining the analyzed systems, purpose and scope of the analysis and the basic assumptions that have been taken,

2. Defining of the fault,

3. Construction of the fault tree (in vertical or horizontal format),

4. Qualitative or quantitative analysis of the fault tree.

The aim of qualitative or logical analysis is to find all reasonably possible combinations of factors operating conditions, environmental conditions, human errors and faults of elements of which could lead to the top event $[14,16]$.

Table 1. The description of the basic events.

\begin{tabular}{|c|c|c|c|c|c|}
\hline Code & Probability & Code & Probability & Code & Probability \\
\hline A & 0.03198 & B & 0.00398 & C & 0.07968 \\
\hline D & 0.02788 & E & 0.01195 & F & 0.00100 \\
\hline G & 0.03187 & H & 0.01596 & I & 0.01992 \\
\hline J & 0.00100 & K & 0.01195 & L & 0.00796 \\
\hline M & 0.00796 & N & 0.00398 & O & 0.00398 \\
\hline P & 0.03187 & Q & 0.04790 & R & 0.00398 \\
\hline S & 0.00239 & \multicolumn{5}{|l}{} \\
\cline { 1 - 6 }
\end{tabular}

A manual solution in a qualitative analysis of the fault tree is currently done only in the case of simple trees (usually a few tens of basic events) otherwise special software products have to be used.

If the parameters of confidence (the likehood of developing) of basic events are known, it is possible to make a quantitative fault tree analysis. The aim of the quantitative analysis, used in presented paper, is to calculate the probability of the top event. We expected that the top event would have occurred during a defined period of the experiment [17 -19].

The Fault Tree Analysis (Fig. 5) was designed using the Cause and Effect Diagram (Fig. 5).

The branch G1 represents the alloy. It is developed to the basic events: A - the temperature of the melt is about $5{ }^{\circ} \mathrm{C}$ below the required temperature, B - the difference between the intended and the actual contents of $\mathrm{Si}$, found by chemical analysis of the casting is greater than $0.5 \%$. The values of the probability of the fault of individual sources are given in Table 1. 


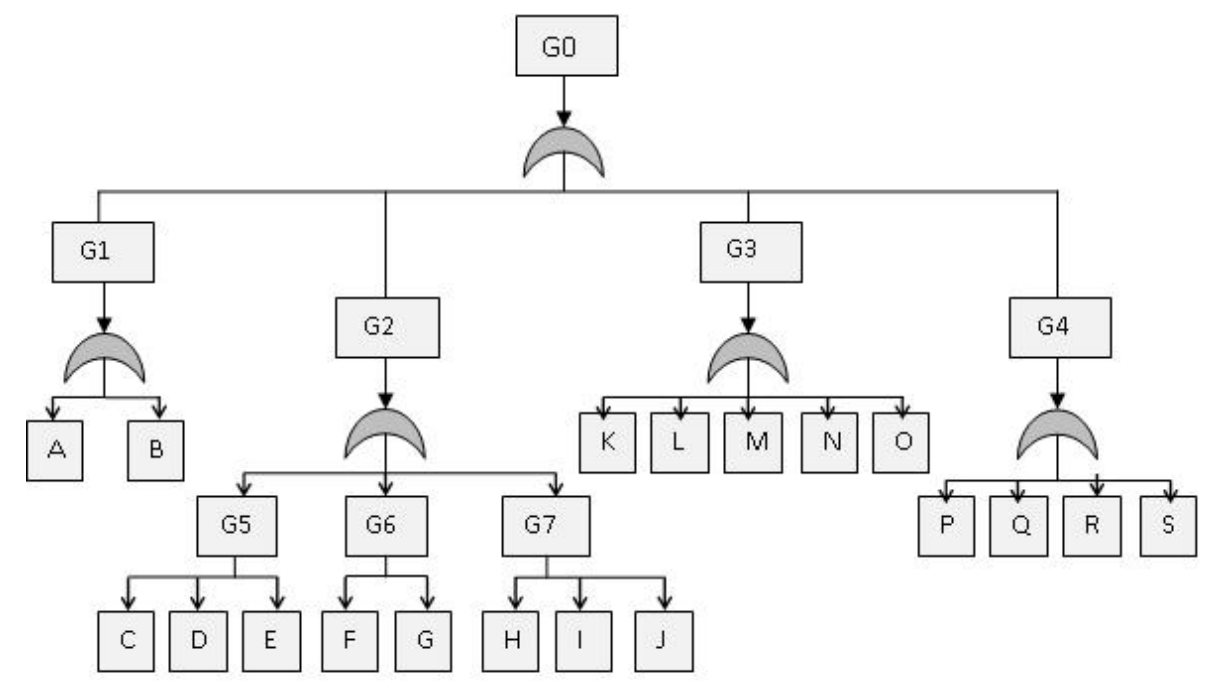

Fig. 5. The Fault Tree Analysis.

The branch G2 represents the test device. It consists of three parts - the horizontal mold, the crucible and the furnace (Fig. 6). Three basic events related to the mold are:

$\mathrm{C}$ - the temperature of the mold decreased by more than $10{ }^{\circ} \mathrm{C}$ below the required $\left(120^{\circ} \mathrm{C}\right)$. It is most frequent the basic event. Its frequency is related to the fact that even small delays in completing the mold (the insertion of baffles into core, the connection of the core with the base plate, the sprue and the cover plate) causes a rapid decrease in temperature, in particular in the end portion of the core with a small cross-section.

D - untight, weakly tightened connections (most often in the contact the core - the sprue or in the mold joint of the sprue) lead to leakage of the melt,

$\mathrm{E}$ - incomplete mold represents the most frequently missing screws, baffles or walls separating the channels.

Two basic events related to the crucible are:

$\mathrm{F}$ - cracking of crucible with the melt did not occur during the experiment. Cracking of the crucible in the furnace may cause severe damage, which requires complicated repairs. If it cracks out of the furnace, spilled melt can cause injury of the founder. The probability of the event was based on the long-term observation in experiments of a similar character.

$\mathrm{G}$ - The crucible with the melt was toppled by negligent founder and the melt was poured.

Basic events related to the furnace are:

$\mathrm{H}$ - "Slow" regulation of the furnace results in a rapid increase in temperature of the melt, the temperature of which exceeds required by more than $5{ }^{\circ} \mathrm{C}$. It may be possible to wait until the temperature of the melt in the crucible decreases the required value. However, the temperature of preheated mold means while undesirable falls. I - the fault of the heater (silit), for example, crack of the silit, the releasing of the sleeve with subsequent discharge,

$\mathrm{J}$ - power fault (the probability of the event was based on the long-term observation). 


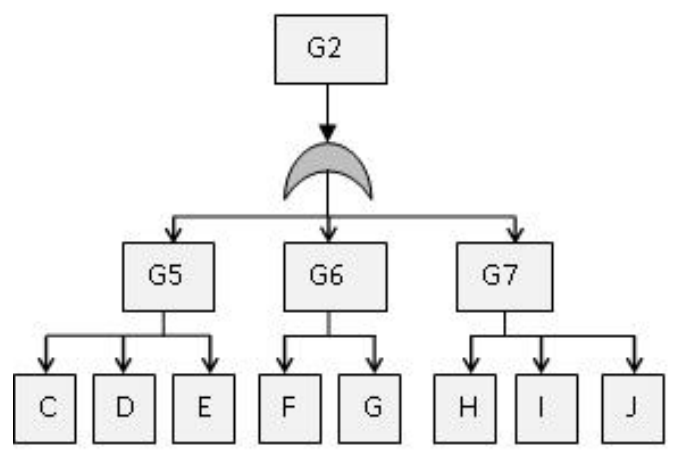

Fig. 6. The branch G2 - the test device.

The branch G3 represents the founder as a human factor. It is developed to five basic events:

$\mathrm{K}$ - inappropriate pouring velocity, required pouring velocity is about $200 \mathrm{~g} / \mathrm{s}$, but it is difficult measurable in practice. If it is too high, the sprue is not able to accumulate melt stream. The melt will partially leak out of the mold with the risk of accidents. Conversely, once the casting time is longer than 5 seconds, the test result is distorted.

$\mathrm{L}$ - the founder missed the pouring basin with the stream of the melt. The melt will partially leak out of the mold,

$\mathrm{M}$ - intermittent stream of the melted alloy results in discontinuities of the casting,

$\mathrm{N}$ - insufficiently removed dross obstructed the channel,

$\mathrm{O}$ - short age of the melt (mold allowed to take more melt than was available in the crucible).

The branch G4 describes the system of the measurement of the temperature of the melt. It consists of two parts: thermocouple and temperature gauge (Fig. 7).

The thermocouple was inserted into the crucible in the furnace when the charge was dissolved. The thermocouple was removed after reaching the required temperature, and the crucible was pulled from the furnace. The surface of the melt was cleaned. The thermocouple was reinserted in to the melt.

The casting may start if the measured temperature was in the above-mentioned range (A) and had met other conditions (the temperature of the mold, above all). Basic events related to the thermocouple are:

$\mathrm{P}$ - over burnt thermocouple,

$\mathrm{Q}$ - damaged protective ceramic case of the thermocouple.

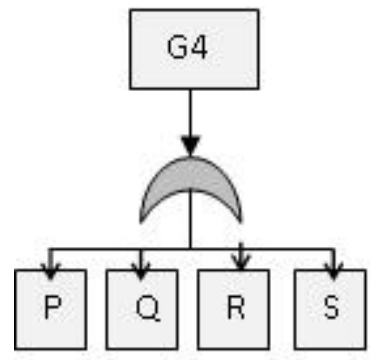

Fig. 7. Branch G4 - the thermocouple and the temperature gauge. 
Basic events related to the temperature gauge are:

$\mathrm{R}$ - the fault of the contact on the input from the thermocouple (insufficiently tight joint),

$\mathrm{S}$ - the short circuit of the thermocouple (unwanted contact between thermocouple wires out of the isolation when handling the thermocouple).

The probability of the top event in the branch G1 is 0.03573 , in G2 is 0.17627 , in $\mathrm{G} 3$ is 0.03535 and in $\mathrm{G} 4$ is 0.07826 .

The probability of the total top event of the analyzed test system is 0.29824 . It is too high value. Practically every third test is unsuccessful.

\section{Monte Carlo Method}

The Monte Carlo method was used as a control calculation. The Monte Carlo method or probability simulation is a means of statistical evaluation of mathematical functions using random samples.

The basic idea of the method is very simple: we want to determine the median of parameter, which is the result of a random action. A computer model of this action is created and after a sufficient amount of overrun simulations we can process data by classical statistical methods, for example, to determine a median and standard deviation [20 - 23].

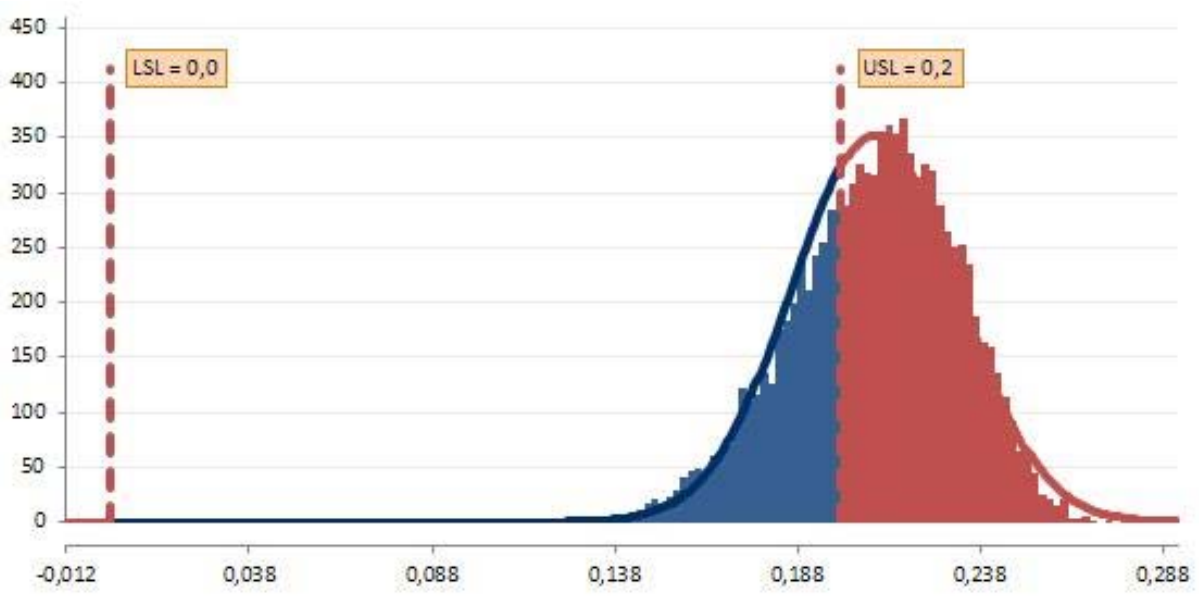

Fig. 8. Probability of the top event.

The probability of the top event was determined during the simulation if the maximum probability of the top event is $p=0.2$ and if the probability inputs of all basic events are taken into account. It is a triangular probability distribution of the values, which are varied between 0 to the probability values shown in Table 1 . The probabilities of other basic events in the branch were considered as constant. The calculation was carried out using software Quantum XL; 10000 repetitions were made.

As can be seen in Fig. 8, required value of the output (probability of the top event) was achieved only to $35.01 \%$. 


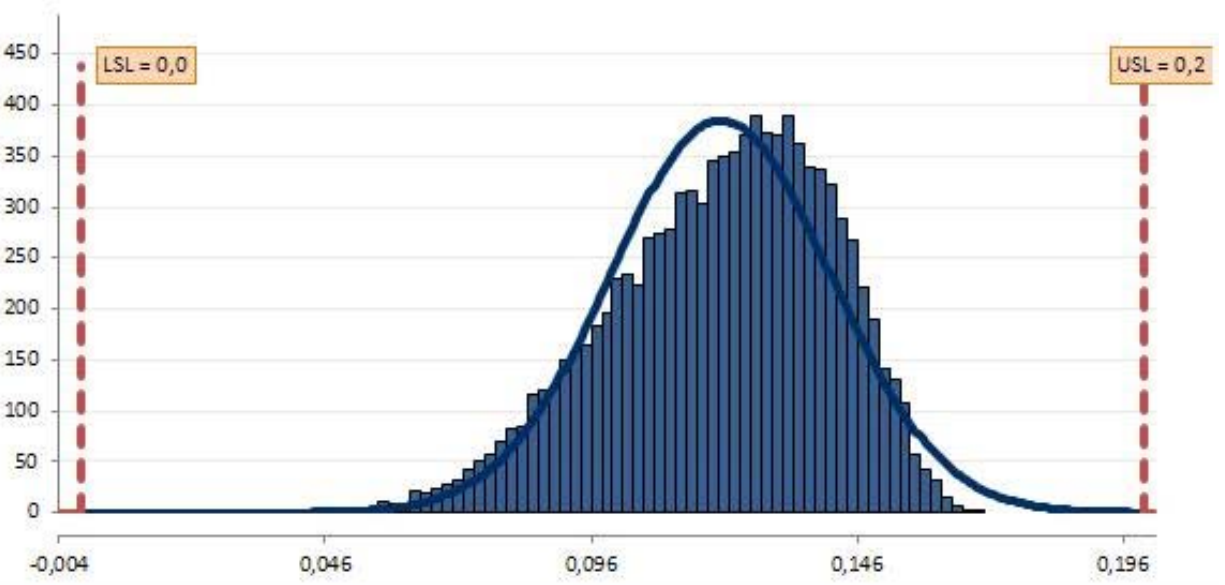

Fig. 9. Probability of the top event in the branch G2.

Fig. 9 shows a partial probability of the top event in branch G2, which appears to be critical. Particularly basic events C, D, G in this branch need to be fixed. Fig. 10 shows the probability of the top event in the branch G4, which appears to be critical, as well, especially basic events $\mathrm{P}$, and Q.

The branch G2 of the device and basic events related to the mold appears to be critical. The corrective action is necessary to focus on these basic events. Reducing 50 $\%$ of the faults of the mold, the probability of the top event decreases to $1 / 4$, whereas by reducing $100 \%$ of faults probability of the top event decreases to $1 / 5$.

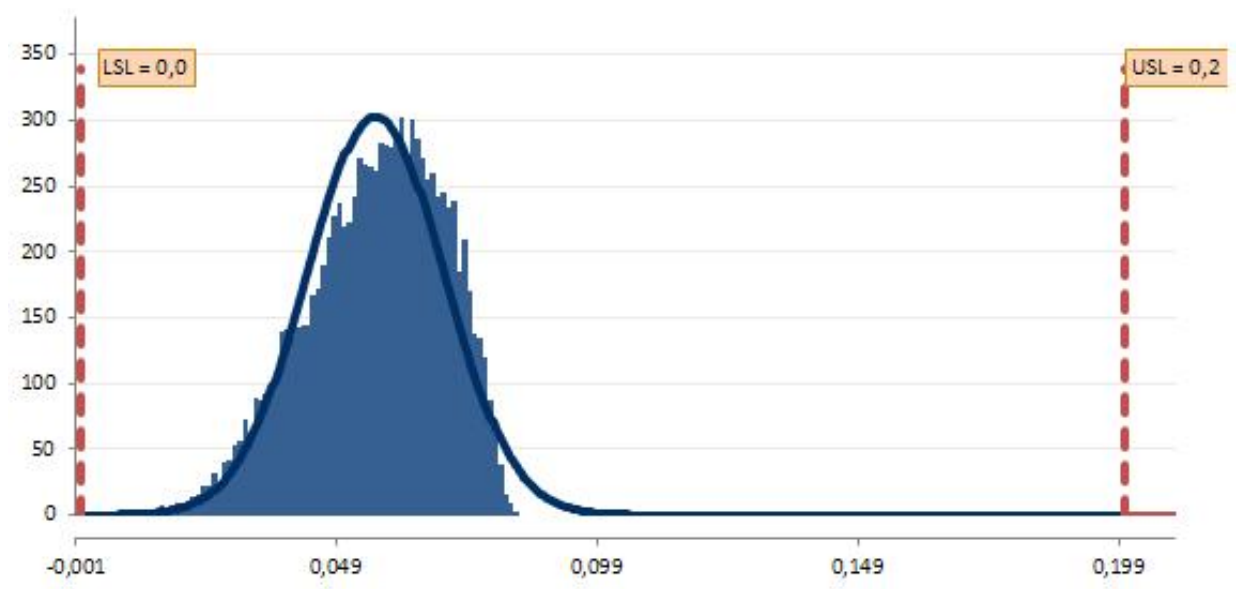

Fig. 10. Probability of the top event in the branch G4

\section{Conclusion}

It has been found that for the probability of the top event in examined process disproportionately is high $(0.29824)$. This fact means that approximately every third of measurements were failing. This fact contributed most basic events bound to 
characteristics of the mold. The critical is the alignment of the temperature of the mold with the temperature of the melt. It requires a very short interval to complete the mold, remove the crucible with the melt from the furnace, remove the thermocouple and the dross and perform casting. The resulting stress is negatively reflected in the work of founders (missing the pouring basin or discontinuous stream of the melt). The problem can be solved to some extent by training the worker who completes (assembles together) the casting mold. It should be noted that he/she must assemble hot and heavy object so quickly as to achieve the least possible temperature drop.

\section{Acknowledgement}

This work was supported by the Slovak Grant Agency for Science KEGA 009TnUAD-4/2011.

\section{References}

[1] VIM International Vocabulary of Basic and General Terms in Metrology (VIM), International Organization for Standardization, Geneva, 1993.

[2] I. Mikulecký, A. Nemečková, R. Palenčár, Basic course of metrology, first ed., Bratislava, 1998, p. 3-20.

[3] J. Vilčko, S. Slovák, Zlievárenská technológia, firsted., Alfa/SNTL, Bratislava/Praha, 1987, p. 24-28. (in Slovak)

[4] Z. Gedeonová, Teória zlievárenských pochodov, Experimentálne cvičenia, first ed., VŠT, Košice, 1981, p.98.(in Slovak)

[5] R. W. Heine, P. C. Rosenthal: Principles of metal casting, first ed.,Des Plaines, Illinois, 1955, p. 191- 285.

[6] T. Elbel, F. Havlíček, Slévárenství, 55 (2007)149-155.(in Czech)

[7] STN 420483 Skúška zabiehavosti ocele na odliatky, SUTN, Bratislava, 1965.(in Slovak)

[8] J. Malkovský, Slévárenství neželezných kovů, first ed., Alfa, Bratislava, 1970, p. 81. (in Czech)

[9] T. Grígerová, R. Kořený,I. Lukáč, Zlievarenstvo neželezných kovov, first ed., Alfa/SNTL, Bratislava/Praha, 1988, p. 290.

[10] Measurement systems analysis (MSA), 4thed. Chrysler Group LLC, Ford Motor Company, General Motors Corporation, 2010.

[11] J. Petrík, T. Tompoš, Slévarenství. 58 (2010) 99-103.(in Slovak)

[12] P. Futáš, J. Petrík, A. Pribulová, In: Proceedings14th SGEM GeoConference on Informatics, Geoinformatics and Remote Sensing, June 19-25, 2014 ConferenceProceedings, Vol. 1, p. 371.doi: 10.5593/SGEM2014/B21/S7.047

[13] P. Futášetal, Key Engineering Materials, 635 (2015) 45-50, doi:10.4028/ www.scientific.net/KEM.635.45

[14] L. Girmanováet al., Nástroje a metódy manažérstva kvality, firsted.,HF TU, Košice,2009.(in Slovak)

[15] IEC 61025 Faulttreeanalysis (FTA). IEC, Geneva, 2007.

[16] B. Rajkumaret al., Journal of Mechanical\& Civil Engineering, 2 (2011) 14-18.

[17] J. Plura, Plánovaní a neustálé zlepšovaní jakosti, first ed., Computer Press, Praha, 2001.(in Czech)

[18] P. L. Clemens: Faulttreeanalysis, http://intra.itiltd-india.com/quality/ QulandRelTools\%5Cfta.pdf [26 March 2014]. 
[19] W. Vesely et al.: FTA handbook with aerospace applications http://www.hq.nasa.gov/office/codeq/doctree/fthb.pdf[26 March 2014].

[20] S. Raychaudhuri: Introduction to Monte Carlo simulation. http://www.informs-sim.org/wsc08papers/012.pdf[26 March 2014].

[21] Z. Barsicet al.: Confirmation of the measurement uncertainty estimation, Metrology for a Sustainable Development, IMEKO WORLD CONGRESS, 2006.

[22] J. Petrík, P. Blaško, In: Proceedings of the scientific conference quality and leading innovation ' 2014 Košice - Hradec Králové, September 19 - 20, 2014, DOI: 10.12776/QALI.V1.\#7, p. 74-84.

[23] D. Knežo, Transfer inovácií, 4 (2012) 178-181. (in Slovak) 